Editorial

\title{
Psychologists and psychiatrists as leaders and managers
}

Volume I Issue I - 2014

\section{Editorial}

Our professional world is changing rapidly, creating unique opportunities and challenges for traditionally trained psychologists and psychiatrists entering leadership positions and assuming management responsibilities. Kelly and Finkelman. ${ }^{1}$ evaluated the advantages and limitations of these professionals in management within the context of the wide array of leadership possibilities and variety of their training and experience. They compared the knowledge, skills and abilities (KSAs) of the psychological professions to the requirements of organizations and management hierarchies ranging from traditional corporations to healthcare, educations, and Non-Governmental Organizations (NGOs).

The authors were concerned about the new, emerging licensures throughout the world, which can be perceived as a threat to the established profession of psychology and psychiatry that were in fact opposed by many of their professional associations. These newer licensures, which allow those with a master's degree to do essentially the same professional practice as those with a doctoral or medical degree, means that those with a doctoral and medical degrees will now have to manage and take leadership positions over those with lesser qualifications. With healthcare and the convergence of a number of industries, it is necessary for psychologists and psychiatrists to maintain a high level of efficiency and effectiveness which can only be achieved by working in teams, which in turn require management and leadership skills.

Unfortunately, many psychologists and psychiatrists have a very negative perception of business. Psychologists and psychiatrists typically have a high opinion of themselves and their profession. Most perceive themselves as having very rigorous training and also high ethical standards. In contrast, they perceive business people as having low ethical standards and less rigorous academic training. As a result, psychologists and psychiatrists often view the practice of business as being effectively "beneath them".

We need to change that perspective in order to get psychologists and psychiatrists excited and motivated about using business and management tools to achieve their goals. If our professions wish to achieve the altruistic goals of changing the world and improving the human experience for as many people as possible, we would do well to adopt a more positive attitude towards business practices. Business is really only a tool to organize a large number people to get things done efficiently and effectively.

Psychologists and psychiatrists have many of the skills, attributes, and dispositions that our business system needs to more effectively serve the needs of society as a whole. The values of 20th century organizations were primarily white male values, e.g. power, control, and

\author{
Jay M Finkelman \\ I-O Business Psychology, The Chicago School of Professional \\ Psychology, USA \\ Correspondence: Jay M Finkelman, I-O Business Psychology, \\ The Chicago School of Professional Psychology, 617 W. 7th \\ Street, Ninth Floor, CA 90017, Los Angeles, USA, Tel 213-615- \\ 7267, Fax 213-283-4222, \\ Email jfinkelman@thechicagoschool.edu
}

Received: June 01, 2014 | Published: June 02, 2014

status. The new generation wants to build organizations whose practices and policies reflect their values. Values that have more to do with embracing diversity, finding meaning in work, and pursuing altruistic goals through their business careers. Psychologists and psychiatrists work most effectively in workplaces that allow more value-based organizations to emerge.

Integrating psychologists and psychiatrists effectively into management and leadership will allow diversity and a value-based workplace organization to flourish and will also facilitate alliances and a more globally friendly approach to business strategy. In making the commitment to learn these management and leadership principles, psychologists and psychiatrists will do well financially despite increasing economic pressures and the intrusion of pseudo-professionals within our areas of practice. This could be a "win-win" for our profession and for business. Hopefully we can inspire curriculum changes in psychology and psychiatry to include more management oriented content and preparation.

\section{Acknowledgments}

None.

\section{Conflicts of interest}

Author declares there are no conflicts of interest.

\section{Funding}

None.

\section{References}

1. Kelly L, Finkelman JM. The psychologist manager: success models for psychologists in executive positions. Hogrefe Publishing, Cambridge, UK. 2013. p.252. 